\title{
A design tool for resource-efficient fabrication of $3 d-$ graded structural building components using additive manufacturing
}

DOI:

10.1016/j.autcon.2017.05.006

\section{Document Version}

Final published version

Link to publication record in Manchester Research Explorer

Citation for published version (APA):

Craveiro, F., Bartolo, H. M., Gale, A., Duarte, J. P., \& Bartolo, P. J. (2017). A design tool for resource-efficient fabrication of $3 \mathrm{~d}$-graded structural building components using additive manufacturing. Automation in Construction, 82, 75-83. https://doi.org/10.1016/j.autcon.2017.05.006

Published in:

Automation in Construction

\section{Citing this paper}

Please note that where the full-text provided on Manchester Research Explorer is the Author Accepted Manuscript or Proof version this may differ from the final Published version. If citing, it is advised that you check and use the publisher's definitive version.

\section{General rights}

Copyright and moral rights for the publications made accessible in the Research Explorer are retained by the authors and/or other copyright owners and it is a condition of accessing publications that users recognise and abide by the legal requirements associated with these rights.

\section{Takedown policy}

If you believe that this document breaches copyright please refer to the University of Manchester's Takedown Procedures [http://man.ac.uk/04Y6Bo] or contact uml.scholarlycommunications@manchester.ac.uk providing relevant details, so we can investigate your claim.

\section{OPEN ACCESS}




\title{
A design tool for resource-efficient fabrication of 3d-graded structural building components using additive manufacturing
}

\author{
F. Craveiro ${ }^{a}$, H.M. Bartolo ${ }^{\mathrm{a}, \mathrm{b}}$, A. Gale ${ }^{\mathrm{c}}$, J.P. Duarte ${ }^{\mathrm{a}, \mathrm{d}}$, P.J. Bartolo ${ }^{\mathrm{a}, \mathrm{c}, *}$ \\ ${ }^{\text {a }}$ Research Centre for Architecture, Urbanism and esign, University of Lisbon, Portugal \\ b School of Technology and Management, Polytechnic Institute of Leiria, Portugal \\ c School of Mechanical, Aerospace and Civil Engineering, University of Manchester, UK \\ d Stuckeman Center for Design Computing, Penn State University, USA
}

\section{A R T I C L E I N F O}

\section{Keywords:}

Additive manufacturing

Building automation

Digital fabrication

Functionally graded materials

Resource-efficient fabrication

\begin{abstract}
A B S T R A C T
The construction sector is under increasing pressure to improve its efficiency and effectiveness, reducing environmental impacts, material use and costs. A computational tool was developed to design and fabricate functionally graded building components. The material composition was defined based on voxel determination in order to design building elements with varying material stiffness. A cement-based conceptual building wall was investigated with a varied material composition, using two different lightweight aggregates, a granulated cork one and the other with expanded clay. This functionally graded material concept applied to lightweight building components will allow producing resource-efficient graded building components tailored to specific loading conditions, minimizing waste generation, emissions and resource consumption.
\end{abstract}

\section{Introduction}

The European Comission is committed to reducing the environmental impact of buildings by improving resource efficiency, as the construction industry is responsible for one third of the Earth's resource consumption, generating huge amounts of solid waste [1]. Annually, the world's production of cement accounts for approximately $7 \%$ of $\mathrm{CO}_{2}$ global emissions, while portland cement is responsible for a large amount of greenhouse gases (GHG) [2]. The production of a ton of portland cement requires $4 \mathrm{GJ}$ of energy, while the manufacture of the clinker accounts for 1 ton of $\mathrm{CO}_{2}$ released into the atmosphere [3]. Therefore, more sustainable construction strategies, enabling to improve energy efficiency and contributing to reduce GHG emissions, are required. On the other hand, a resource efficient construction sector with lightweight structural components will help to reduce waste generation, emissions and global resource consumption [4].

Additive Manufacturing (AM) technologies, a class of manufacturing processes, in which a part is built by adding layers of material upon one another [5-8], has been exploited for the construction sector. Khoshnevis [9] developed a concept for the automatic fabrication of a house called Contour Crafting. This system consists of the automatic fabrication of building walls layer by layer, until the creation of a formwork filled with mortars mainly composed by cement. Lim et al. [10] developed a concrete printing strategy based on the extrusion of cement mortars to produce 3D customized products. Gosselin et al. [11] developed a system based on an extrusion print head mounted on a 6 axis robotic arm, in which the fabrication process includes a mortar premix and an accelerating agent to accelerate the setting of mechanical properties after extrusion. Dini [12] developed binder jetting technology called "D-Shape", using sand and a binder to create stonelike structures to build medium size structures. The Dutch company DUS Architects developed an extrusion-based printer to produce a canal house in Amsterdam [13]. Real scale prototypes were developed to print homes, namely by the Chinese company Yingchuang [14], and the World's Advanced Saving Project [15]. In the construction area, AM processes can be used for both off-site and on-site applications, for the production of construction components or repairing applications (Fig. 1).

Current Additive Manufacturing (AM) technologies are commonly used to fabricate physical elements with homogeneous material properties [16,17], and not to produce physical elements with spatially varying compositions, characterized by a gradual spatial change in composition and microstructure. Such structures were defined by [18] as Functionally Graded Materials (FGM).

Craveiro et al. [19,20] proposed a fabrication system, called "RapidConstruction", to produce multi-material structures using several materials (cement, polymers and clay). This fabrication system comprised a computer controlled gantry crane integrating multi-deposition

\footnotetext{
* Corresponding author at: School of Mechanical, Aerospace and Civil Engineering, The University of Manchester, UK

E-mail address: paulojorge.dasilvabartolo@manchester.ac.uk (P.J. Bartolo).
} 


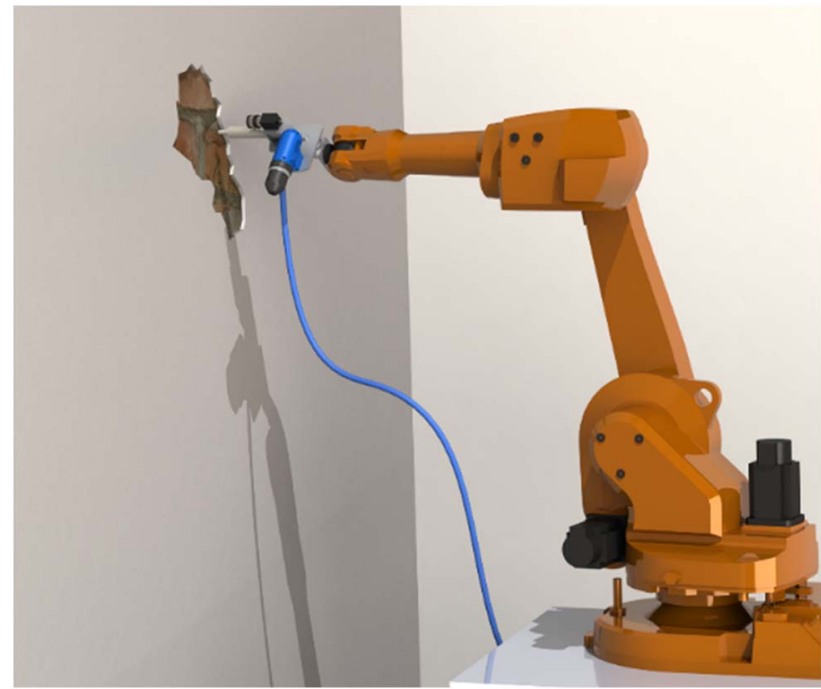

Fig. 1. CAD model concept for AM for repairing applications.

heads with various degrees of freedom. A functional prototype was developed with three extrusion heads. The the first extrusion head was used to process different composite materials (clay with natural fibers) and composite concrete for contour paths, smoothed by lateral trowels. A second head created composite meshes and the third one extruded filling material, both producing polyuretane polymers with different compositions [21-24].

Cementitious materials, particularly concrete, are the most widely used materials in the world. Every year, more than $1 \mathrm{~m}^{3}$ is produced per person worldwide, taking into account that vast quantities of cement and concrete produce $5-8 \%$ of $\mathrm{CO}_{2}$ [25]. There is an increasing pressure for innovation and sustainability in the construction sector, and the use of alternative aggregates processed from waste materials or natural and renewable materials is a good solution to reduce the depletion of earth's natural resources [26]. To process functionally graded concrete, using cork and expanded clay, a printing head capable of metering the additives during emplacement of the concrete will be used [27]. A computational tool was developed to design and fabricate functionally graded building components made with cement-based aggregates, with different amounts of cork or clay, depending on structural and thermal constraints. This paper describes in detail this computational tool.

\section{Design tool for functionally graded components}

The computational tool was designed to control the material composition variation of conceptual building walls, using lightweight aggregates in specific areas to satisfy structural and environmental needs, in order to reduce its weight, and keeping its structural performance. The workflow overview is illustrated in Fig. 2.

The computational tool includes a parametric design tool and a structural analysis (Finite Element Analysis, FEA) to provide an integrated generative tool, allowing the definition of the material composition of the building components. A visual programming tool called Grasshopper (Rhinoceros plugin) is used to parametrically design the 3D construction elements using iconic components interactively manipulated by the user [28]. These components are boxes, representing shapes and operations, and connectors linking the boxes, creating dataflows between components, where the output of a component is the input to another. The parametric tool comprises two modules. The first

Fig. 2. Flowchart representing the strategy to produce FGM structures.
Set up the initial material properties (homogeneous structure)

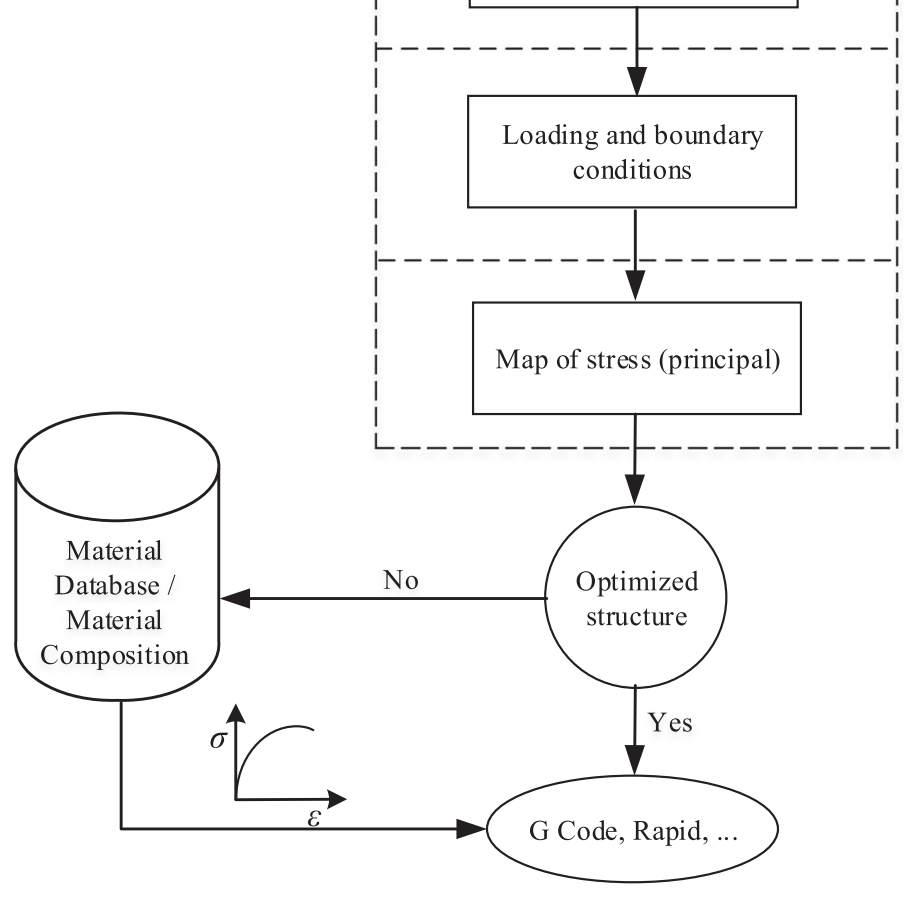

CAD - Definition of a specific building element 

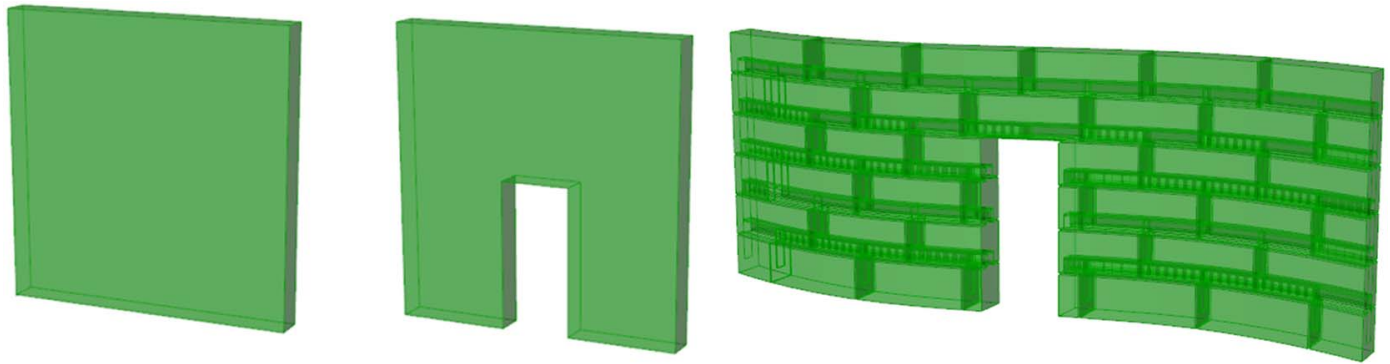

Fig. 3. Examples of different building wall geometries generated with the parametric design tool.

module enables the design of straight or curved building walls, with or without openings (Fig. 3), as well defining the location of applied loads and supports for simulation purposes (Fig. 4). The selected wall design is then exported as a neutral CAD file (e.g., IGES, Parasolid, STEP) to be used for simulation purposes.

The FEA software Ansys (Ansys inc) is used to structurally simulate the design building elements. The 3D model is imported into the simulation software (Fig. 5a), the FEA mesh is created and appropriate loads and boundary conditions applied (Fig. 5b). The building element is assumed to be homogeneous and material properties assigned considering that the structure is made of concrete. After simulation, a map of principal stress is obtained as illustrated in Fig. 5c, where a colour gradient is observed with dark blue regions corresponding to the lowest stress values and yellow regions to the highest ones (absolute values). The maximum principal stress criteria also known as the Coulomb criteria is usually considered to predict the failure of brittle materials, such as the ones used in this research [29]. However other criteria such as the Von Mises stress can also be used. The resulting data are analyzed by the computational tool, aiming to obtain an optimal and uniform map of stress, which attributes distinct material properties according to structural needs, considering that a higher principal stress region requires a stronger material, preventing structural failure by surpassing the yield strength of the material. The material definition is performed by using a material database where the materials are characterized by empirical models correlating composition and compressive stenght. Thermal properties are also included.

Building elements are discretized into very small cubic elements of volume called voxels. Material compositions are assigned to each voxel. Voxel based methods are based on discrete units and their accuracy is related to the number of voxels used in the model. The code allows defining the quantity of voxels to achieve the desired accuracy. Results from the FEA can be exported to Grasshopper as a .CSV file, including FEA x-y-z node coordinates and associated principal stress, overlapping the voxels (Fig. 6). The mapping between voxels and corresponding FEA nodes is critical, in order to assign material properties. In this case, each voxel assumes the average value of principal stress of the comprised node values. This average value is then used to select the corresponding material considering the mechanical empirical models included in the database.

Two case studies were investigated, based on the outputs of the conceptual building wall illustrated in Fig. 5, one with a variable percentage of granulated cork and another with a variable percentage of expanded clay, both mixed with concrete. The developed tool, shown in Fig. 7, will then assign in each case different material components ratios to each voxel, which assumes a specific material composition.

\subsection{Material database}

In this research, a conceptual building wall was investigated with a varied material composition, using lightweight aggregates in specific areas to reduce its weight, though keeping its structural performance. Two lightweight aggregates were selected to produce functionally graded concretes, one using granulated cork and the other expanded clay. The percentage of these lightweight aggregates is spatially distinct according to stress concentration requirements, varying in an inversely proportional way with the principal stress values, taking into account a safety factor. Properties were obtained from [30,31].

Cork is a natural and sustainable raw material and Portugal is the largest cork producer in the world [32]. Cork is a cellular material (Fig. 8) and its remarkable properties seems to come from the

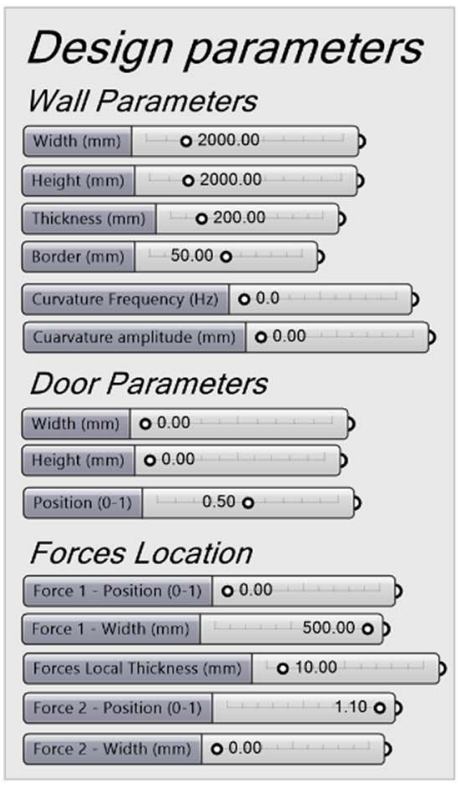

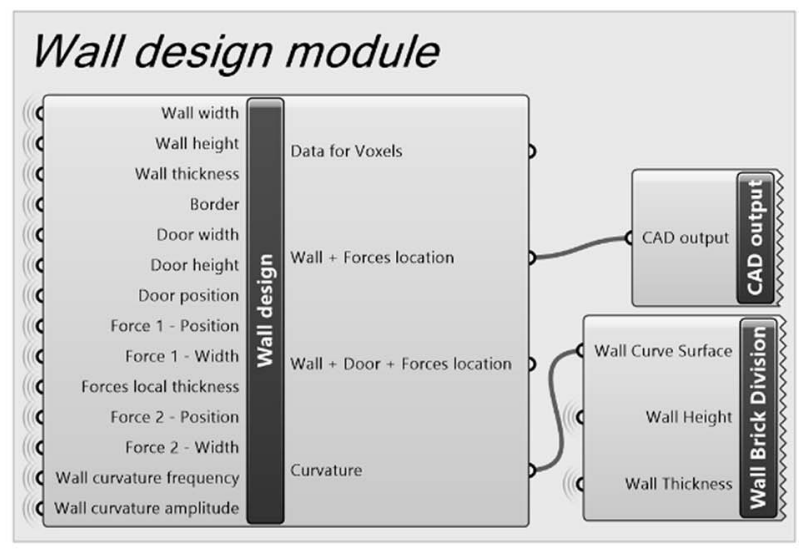

Fig. 4. Parametric wall design module using Grasshopper. 
a)

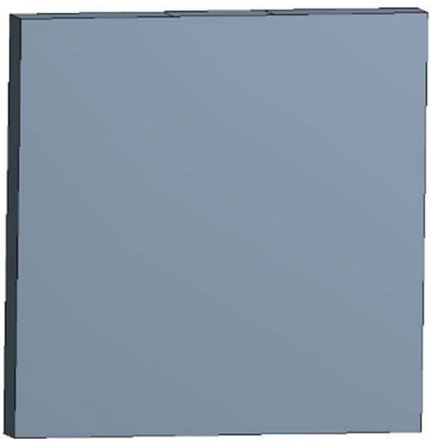

b)

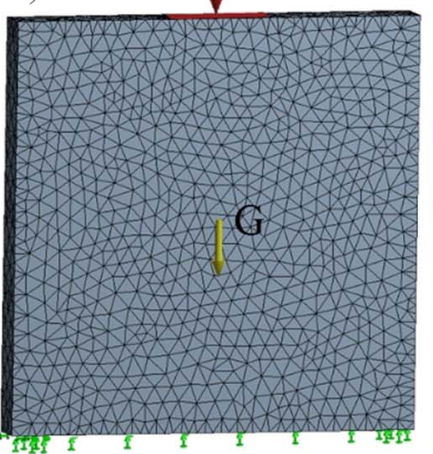

c)

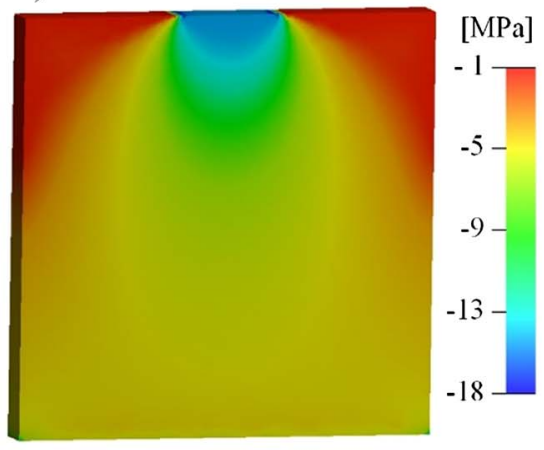

Fig. 5. Simulation procedure: a) CAD model definition, b) FEA mesh, loads and boundary conditions specification, c) Principal stress results.

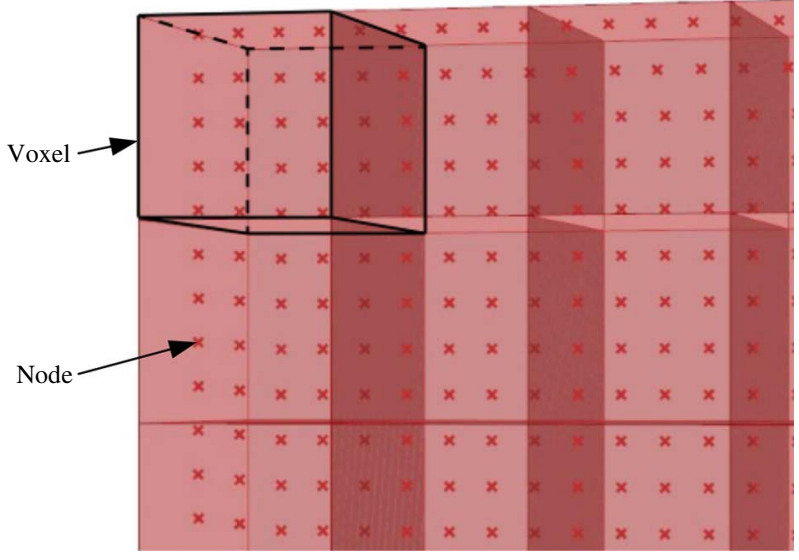

Fig. 6. Example of node overlapping voxels.

combination of aligned, prismatic closed cells and a particular structural arrangement [33]. This natural material has a high coefficient of friction, resilience, high energy absorption, excellent insulation properties and near-zero Poisson coefficient, which makes it an ideal material for a variety of applications. Only $25 \%$ of cork harvested is used for the production of high quality punched bottle stoppers and the other $75 \%$ is considered waste, being used for thermal and acoustic insulation and anti-vibration construction elements, decorative products, shoe making, etc. [34,35]. These granules have low density and can be used as lightweight aggregates for making concrete and mortars with thermal and acoustic insulation properties [36].

According to [33], the compressive strength depends on the cork quantity (expanded cork granules size 4/5), as follows:

$\sigma=25.289-0.6381 c$

where $\sigma$ is the compressive strength (MPa) and $c$ is the cork quantity (\% volume). The material density varies with the compressive strength according to Eq. 2:

$d c=1434.718+40.323 \sigma$

Where $d c$ is the material density and $\sigma$ is the compressive strength (MPa).

Expanded clay is produced by firing natural clay and its lightweight is due to a high proportion of semi-closed pores which account for up to $90 \%$ of the particle volume $[37,38]$. The voids and pores (Fig. 9) within these aggregates enhances its thermal and acoustical insulating properties [39]. Expanded clay aggregates are suitable for construction
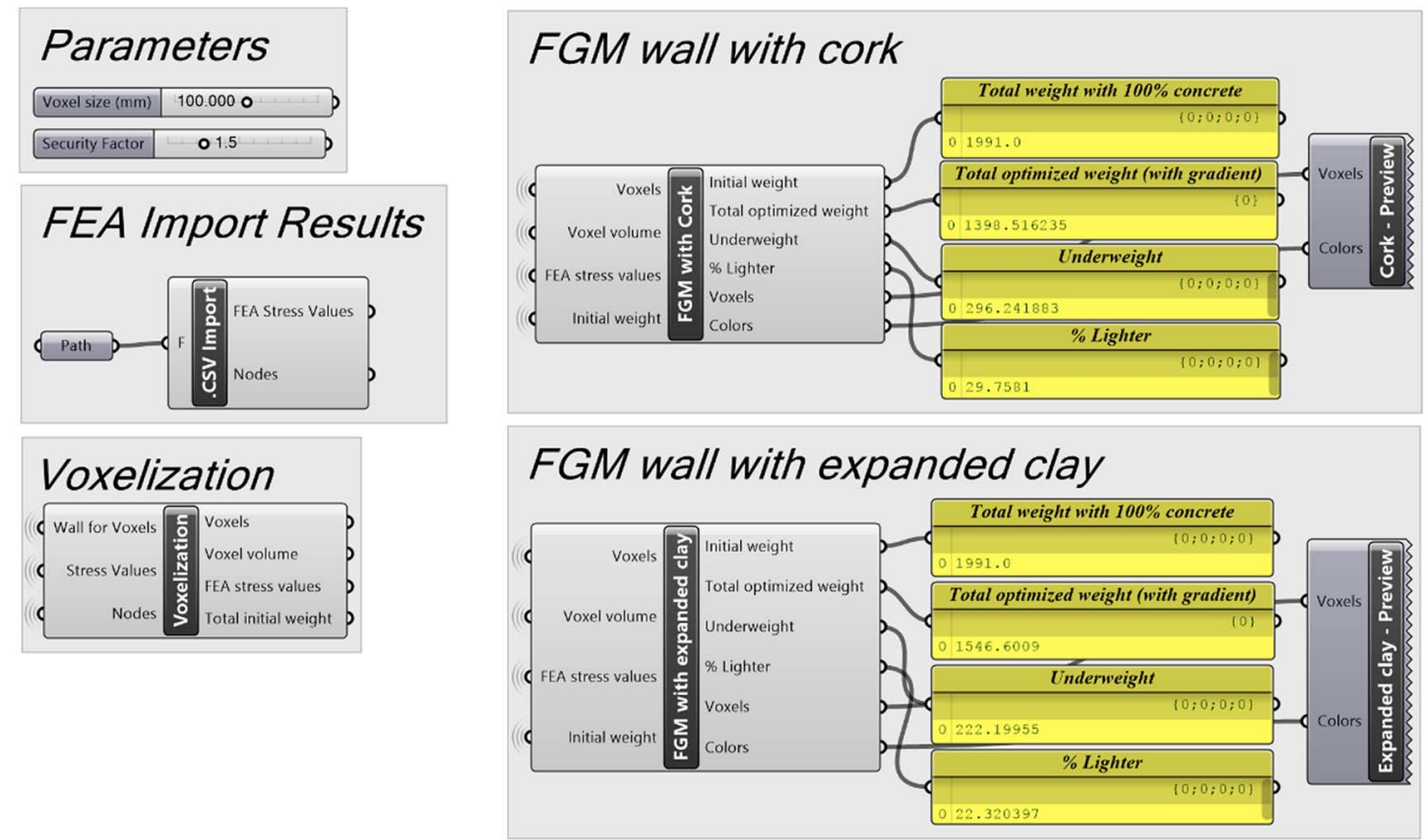

Fig. 7. The software tool developed in Grasshopper. 

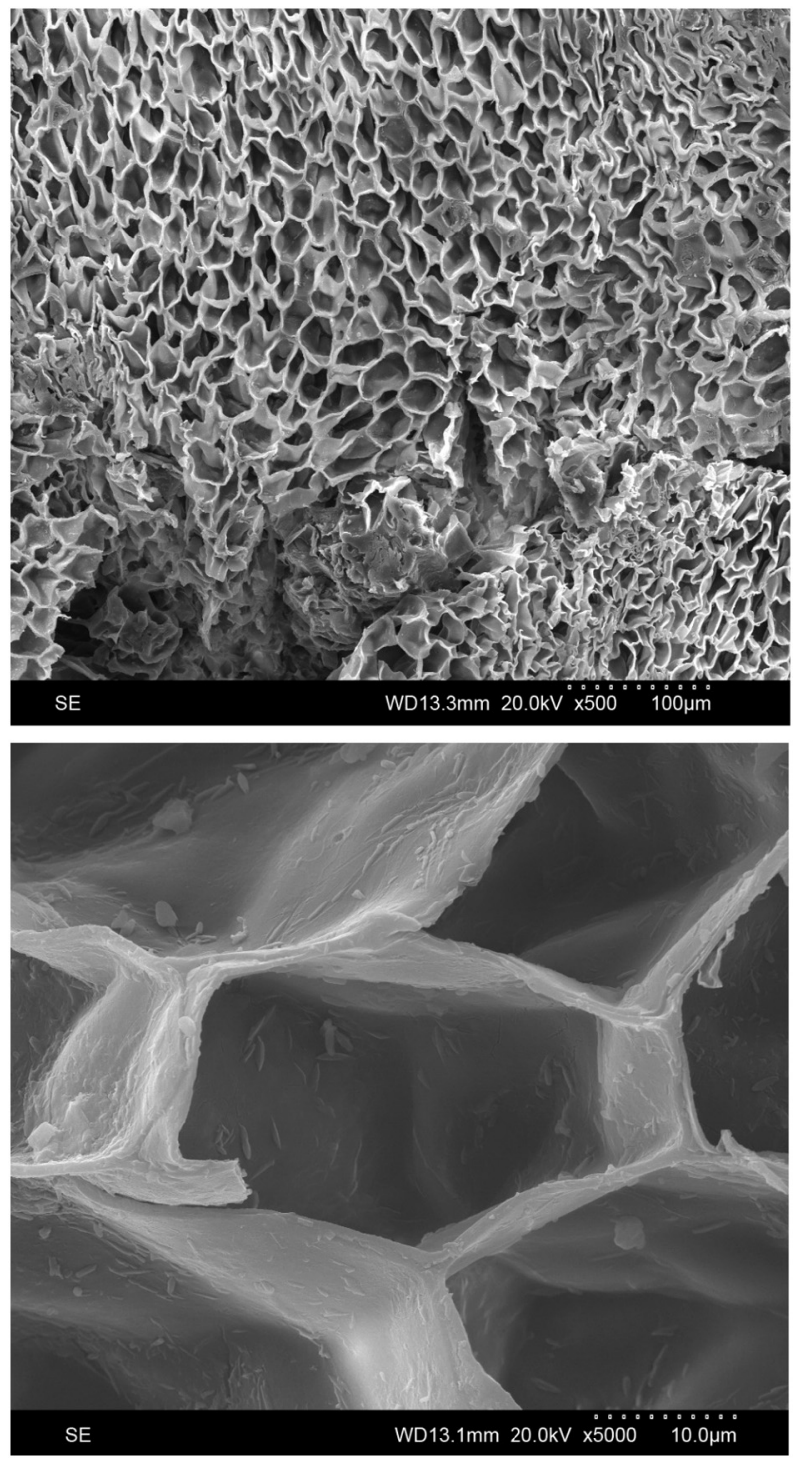

Fig. 8. Scanning electron microscope (SEM) images of the morphology of natural cork cellular structure at different magnifications, where SE is the secondary electron image and WD the working distance.

purposes, varying in composition, density, surface texture, porosity and water absorption capacity [37].

According to $[27,28]$, the compressive strength depends on the expanded clay quantity, as follows:

$\sigma=26.140-41.824 e$

where $\sigma$ is the compressive strength (MPa) and $e$ is the expanded clay quantity (\% volume). Material density varies with the compressive strength according to Eq. 4:

$d e=1741.7+27.108 \sigma$

where de is the material density and $\sigma$ is the compressive strength (MPa).

\section{Case studies}

\subsection{Concrete-cork and concrete-expanded clay functionally graded components}

A construction element of $2 \mathrm{~m} \times 2 \mathrm{~m} \times 0.2 \mathrm{~m}$ was modelled using a FEA mesh of tetrahedral elements. Tetrahedral meshing is the default type in FEA software tools as tetrahedral elements can be used to
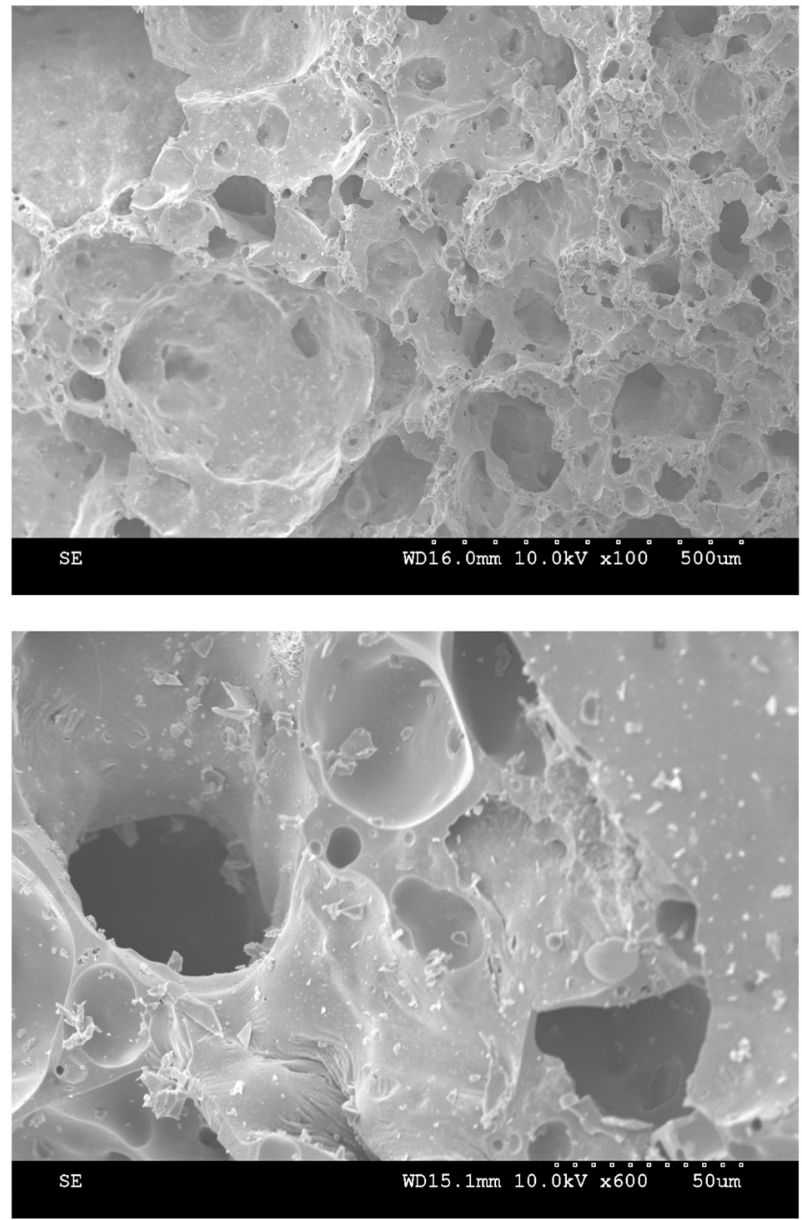

Fig. 9. SEM images of an expanded clay particle, where SE is the secondary electron image and WD the working distance.

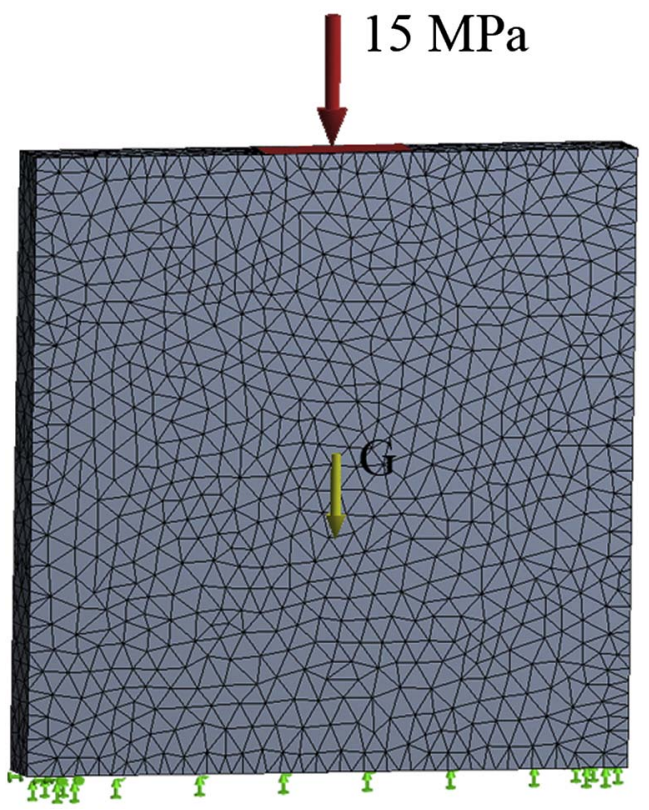

Fig. 10. Selected building wall with the FEA mesh, loads and boundary conditions.

succecefully modelled any 3D structure, allouwing also adaptive mesh refinement. A convergence analysis was performed and a non-uniform mesh size considered, being the mesh more dense in critical areas such as applied loads and boundary conditions. To garantie that there is 


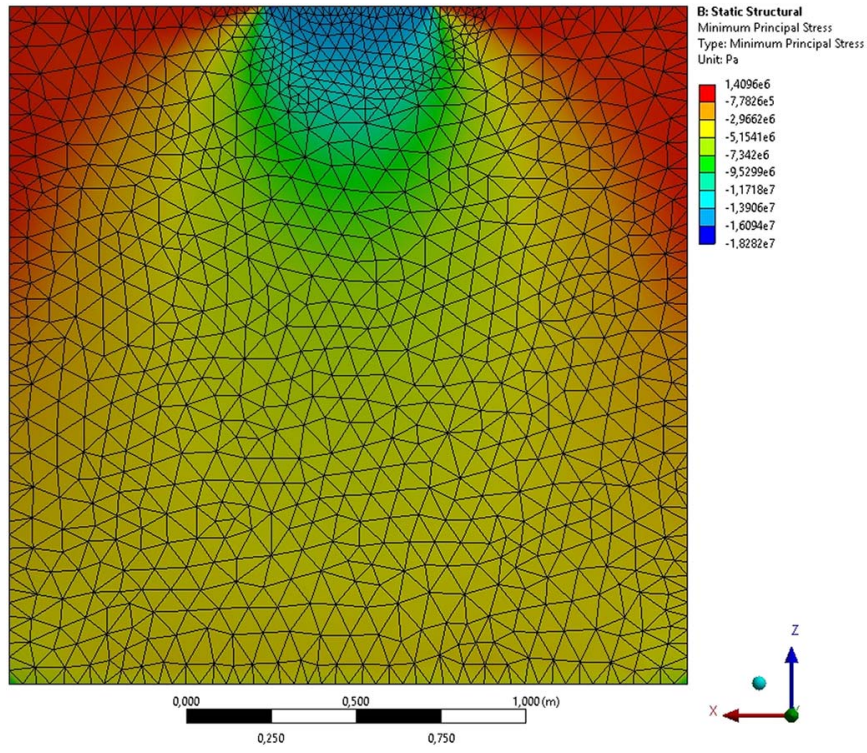

Fig. 11. Principal stress map.

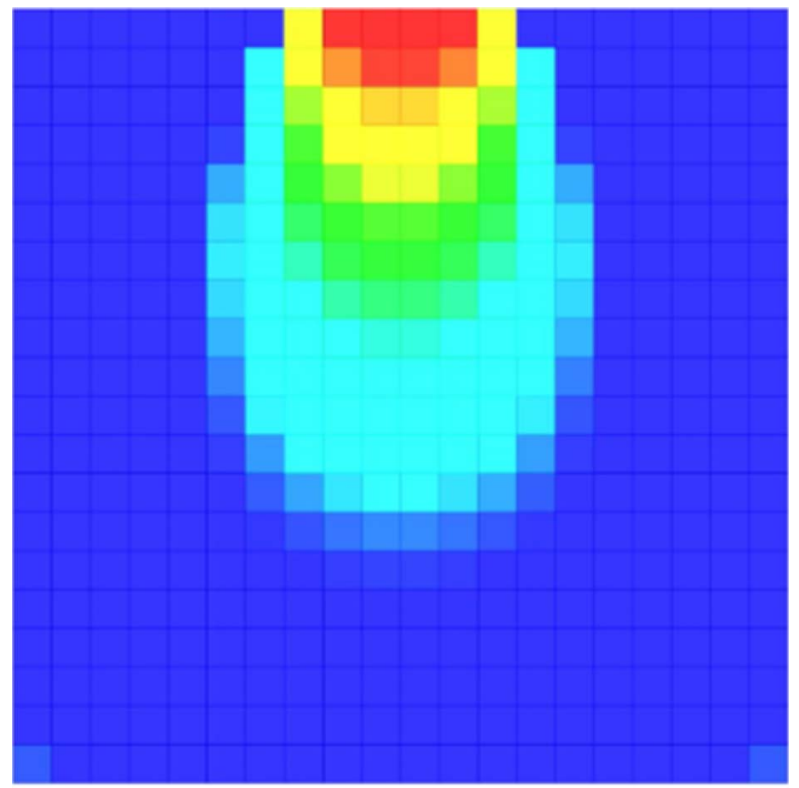

Cork in concrete paste [\% of volume]

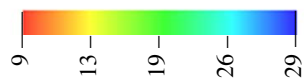

Fig. 12. Cork percentage of the concrete paste volume assigned to each voxel.

always an element node inclosed in a voxel, the element size was defined to be smaller than each voxel. The effect of gravity and an applied pressure of $15 \mathrm{MPa}$ at the upper side of the wall, simulating the effect of a beam was considered. The element was constrained from movement in all directions at the lower side of the wall (Fig. 10). The map obtained of principal stress is shown in Fig. 11. Based on the determined stresses, the percentage of additive (cork or expanded clay) in the concrete was spatially varied to accommodate the stresses. This led to an assigment of a specific amount of cork or expanded clay in the concrete for each voxel. For cork, this assignment is presented in Fig.12. This material distribution guarantees the structural stability of the concrete element. Similarly, Fig. 13 shows the expanded clay percentage of the concrete paste volume assigned to each voxel.

Table 1 presents the building wall mass for different material compositions. In the first case, using cork as the lightweight aggregate,

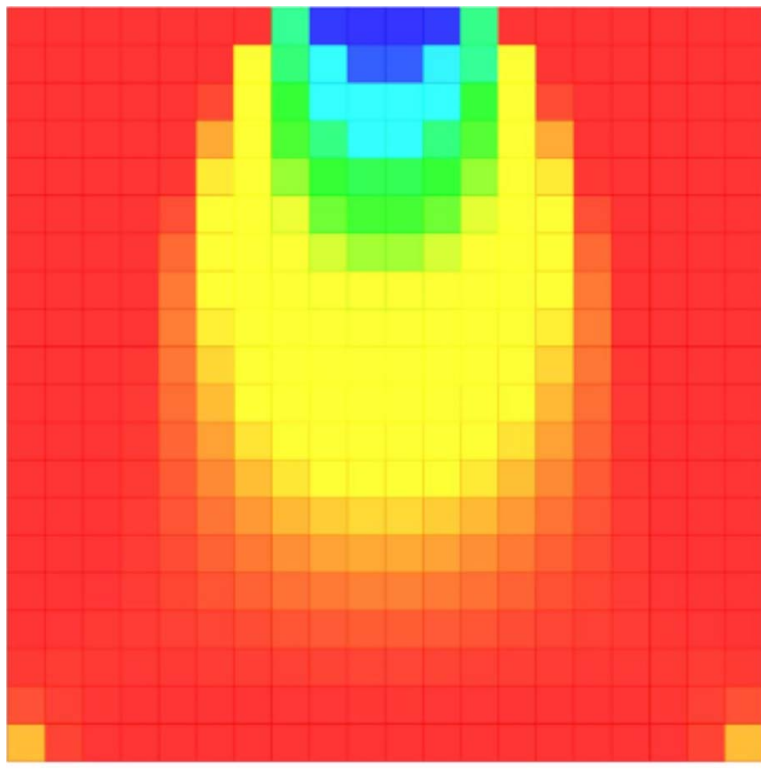

Expanded clay in concrete paste [\% of volume]

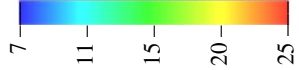

Fig. 13. Expanded clay percentage of the concrete paste volume assigned to each voxel.

Table 1

Building wall mass with different material compositions.

\begin{tabular}{ll}
\hline Material Solution & Building wall mass \\
\hline Concrete & $1991 \mathrm{~kg}$ \\
Concrete with cork & $1398 \mathrm{~kg}(-27 \%)$ \\
Concrete with expanded clay & $1546 \mathrm{~kg}(-22 \%)$ \\
\hline
\end{tabular}

there is a loss of $27 \%$ in weight compared to a standard concrete solution. In the second case study, where the lightweight aggregate is expanded clay, there is a loss of $22 \%$ in weight compared to a standard concrete solution.

\subsection{Thermal performance}

The Ecotect Analysis software (Autodesk) was used to investigate the thermal performance of the obtained functionally graded wall solutions. This software allows the calculation of total energy consumption by a building on an annual basis, using a global weather information database. Two European cities were considered with different weather characteristics: Lisbon (Portugal) located in the South and Manchester (England) in the North.

To investigate the thermal performance, a south-facing building wall was selected using a standard building room with $2 \mathrm{~m} \times 2 \mathrm{~m} \times 2 \mathrm{~m}$ (Fig. 14) to analyze the monthly heating and cooling loads needed to maintain the comfort temperature $\left(18-26^{\circ} \mathrm{C}\right)$, over a year long period.

Due to limitations of the Ecotect Analysis software, there is a need to represent the 3D wall in a two-dimensional (2D) way. Taking into account that the wall has the same features as its width, it was decided to use a $2 \mathrm{D}$ grid composed of square elements corresponding to the $3 \mathrm{D}$ voxels (Fig. 15). Each element, with $0.2 \mathrm{~m}$ of thickness, had specific associated features, such as thermal conductivity, specific heat and density. For each material composition, the thermal conductivity was obtained using a simple mixture law, as follows:

$p_{\text {mixture }}=p_{A} \times d_{A}+p_{B} \times d_{B}$

where $p_{a}$ is the volume fraction of granular cork or expanded clay, $d_{a}$ is 


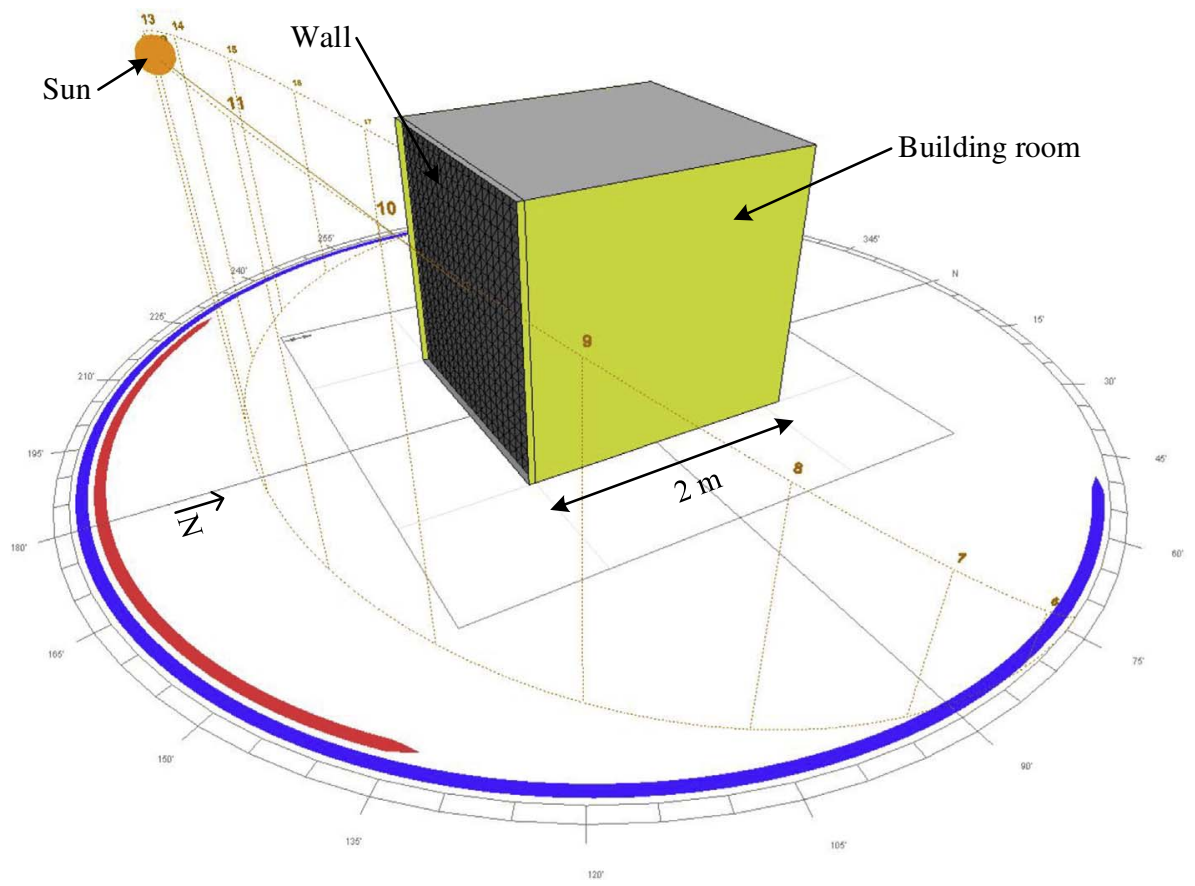

Fig. 14. Standard building room using Autodesk Ecotect Analysis. the thermal conductivity of granular cork or expanded clay, $p_{b}$ is the volume fraction of concrete and $d_{b}$ is the thermal conductivity of concrete. A similar procedure was used to calculate the specific heat and density for each element.

Considering a full air conditioning system with 95\% efficiency it is possible to obtain the monthly heating and cooling loads needed to maintain the comfort temperature over a one-year period in Lisbon (Fig. 16) and Manchester (Fig. 17), taking into account the different material compositions of the building wall defined in Table 1.

Figs. 16 and 17 show that the material compositions with functionally graded concrete containing cork granules and expanded clay are better energy efficient solutions. Results are summarized in Table 2.

\section{Conclusions}

The construction industry faces huge challenges to respond to new global issues, to embrace sustainability and innovation through novel materials and technologies. On the other hand, the construction sector is under increasing pressure to improve its efficiency and effectiveness, reducing environmental impacts, material use and costs.

A computational tool was developed to design and fabricate functionally graded building components to improve material use and structural efficiency. Current AM technologies, commonly used to fabricate physical elements with homogeneous material properties, or deposit multiple materials in a discrete way, are not appropriate to produce physical elements with spatially varying compositions, characterized by a gradual spatial change in composition and microstructure.

This tool was designed to control the material composition variation of the building components to improve strength, reduce weight and material usage. The material composition was defined based on voxel determination to design building elements with varying material stiffness.

To test the proposed software tool, a cement-based conceptual building wall was investigated with a varied material composition, using two different lightweight aggregates, cement-granulated cork or cement-expanded clay. The percentage of these lightweight aggregates was spatially distinct according to stress concentration requirements. The thermal performance of these functionally graded building wall solutions was also investigated using the Ecotect Analysis software from Autodesk. Currently, a novel multi-material printing head is being developed to allow the fabrication of the structures defined by the computational tool. Printed functionally graded structures will be used to assess the predicted numerical results.

Finally, this strategy will enable resource-efficient graded building components tailored to specific loading conditions, minimizing waste

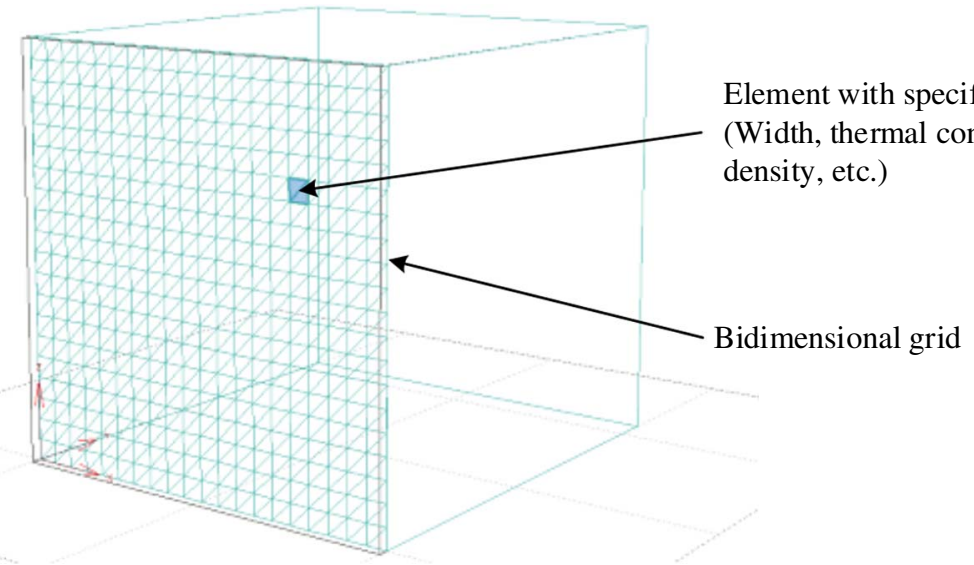

Fig. 15. Detail the bi-dimensional grid composed by square elements. 
Concrete

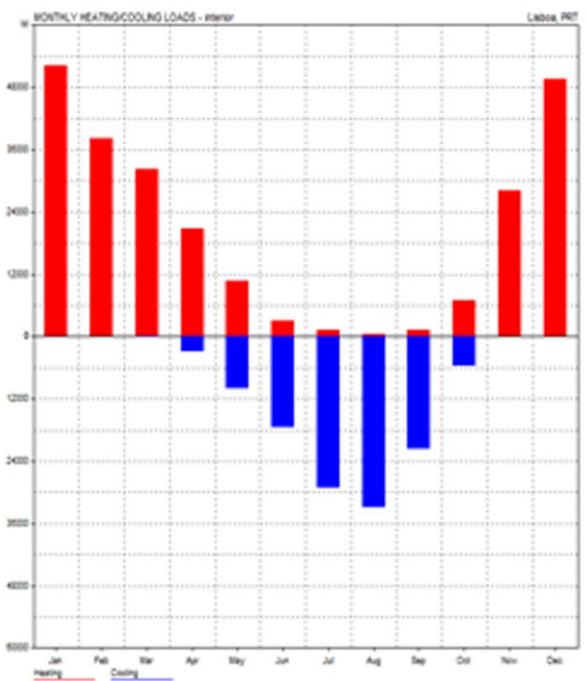

Max Heating: $178 \mathrm{~W}$ at 10:00 on 31st January

Max Cooling: $328 \mathrm{~W}$ at 16:00 on 29th August

Heating: $245315 \mathrm{Wh}$

Cooling: $119819 \mathrm{Wh}$

Total: 365134 Wh
Concrete with cork

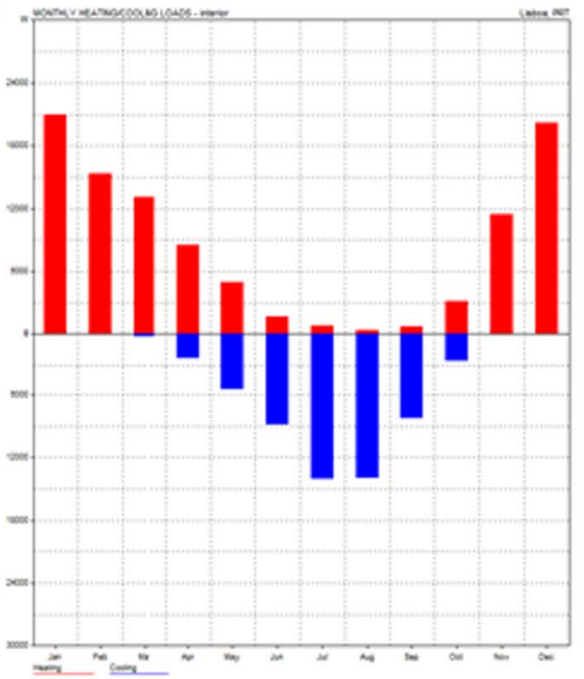

Max Heating: $70 \mathrm{~W}$ at 10:00 on

31st January

Max Cooling: $131 \mathrm{~W}$ at 16:00 on

15th July

Heating: $101316 \mathrm{Wh}$

Cooling: $55677 \mathrm{Wh}$

Total: $156993 \mathrm{Wh}$
Concrete with expanded clay

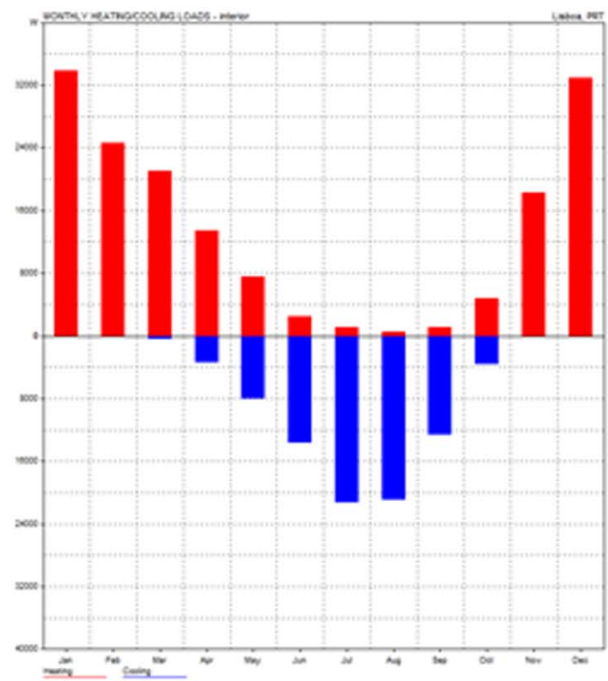

Max Heating: $115 \mathrm{~W}$ at 10:00 on 31st January

Max Cooling: $232 \mathrm{~W}$ at 16:00 on

15th July

Heating: $161406 \mathrm{Wh}$

Cooling: $84083 \mathrm{Wh}$

Total: 245489 Wh

Fig. 16. Monthly heating and cooling loads for Lisbon considering: a) 100\% concrete wall, b) functionally graded concrete wall with cork granules and c) functionally graded concrete wall with expanded clay.

Concrete

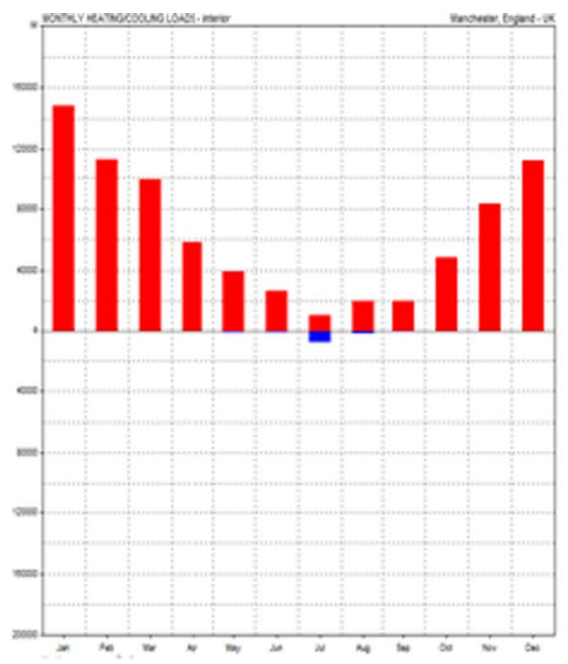

Max Heating: $313 \mathrm{~W}$ at 10:00 on 17th January

Max Cooling: $271 \mathrm{~W}$ at 14:00 on 3rd July

Heating: $780458 \mathrm{Wh}$

Cooling: $13352 \mathrm{Wh}$

Total: $793810 \mathrm{Wh}$
Concrete with cork

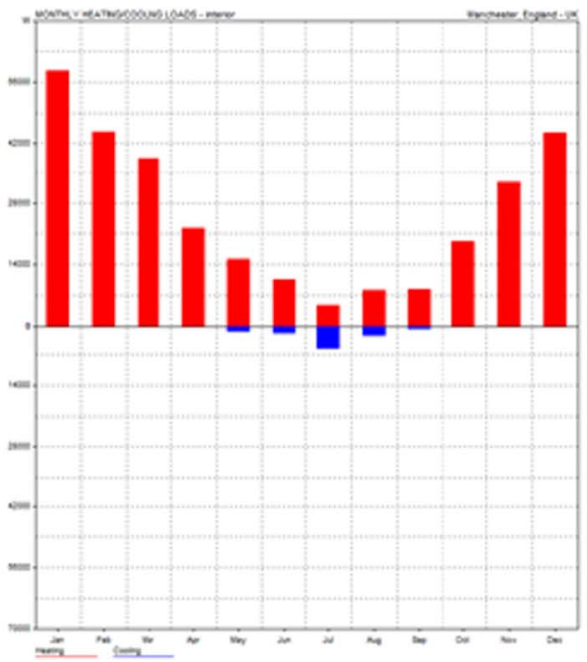

Max Heating: $70 \mathrm{~W}$ at 10:00 on 31st January

Max Cooling: $131 \mathrm{~W}$ at 16:00 on 15th July

Heating: $307612 \mathrm{Wh}$

Cooling: $12051 \mathrm{Wh}$

Total: $319663 \mathrm{Wh}$
Concrete with expanded clay

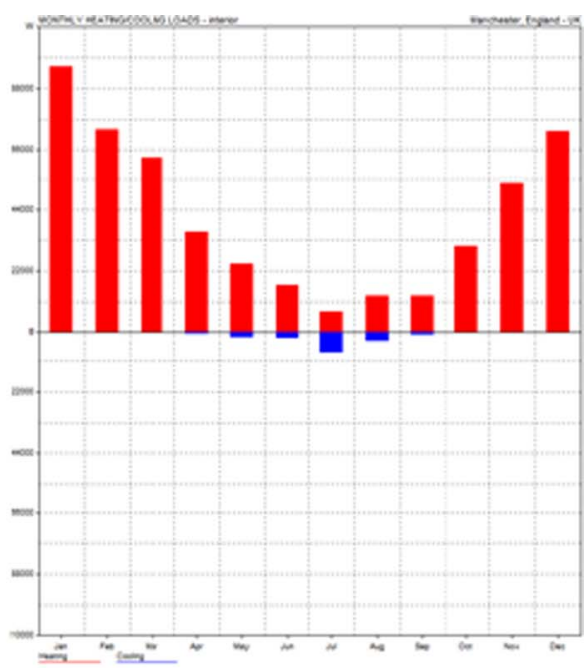

Max Heating: $203 \mathrm{~W}$ at 10:00 on 17th January

Max Cooling: $204 \mathrm{~W}$ at 14:00 on 1st July

Heating: $500829 \mathrm{Wh}$

Cooling: $16231 \mathrm{Wh}$

Total: $\mathbf{5 1 7 0 6 1} \mathrm{Wh}$

Fig. 17. Monthly heating and cooling loads for Manchester considering: a) 100\% concrete wall, b) functionally graded concrete wall with cork granules and c) functionally graded concrete wall with expanded clay. 
Table 2

Heating and cooling loads needed to maintain the comfort temperature over a one-year period.

\begin{tabular}{lll}
\hline Material Solution & Total loads \\
\cline { 2 - 3 } & Lisbon & Manchester \\
\hline Concrete & $365,134 \mathrm{Wh}$ & $793,810 \mathrm{Wh}$ \\
Concrete with cork & $156,993 \mathrm{Wh}(-57 \%)$ & $319,663 \mathrm{Wh}(-60 \%)$ \\
Concrete with expanded clay & $245,489 \mathrm{Wh}(-33 \%)$ & $517,061 \mathrm{Wh}(-35 \%)$ \\
\hline
\end{tabular}

generation, $\mathrm{CO}_{2}$ emissions and resource material consumption.

\section{Acknowledgements}

This research work was supported by a grant (SFRH/BD/105404/ 2014) funded by the Portuguese Science Foundation. This work was supported by the Portuguese Cork Company AMORIM.

\section{References}

[1] European Commission, Resource Efficiency in the Building Sector, DG Environment, Rotterdam, 2014.

[2] P.K. Mehta, Reducing the environmental impact of concrete, Concr. Int. 23 (2001) 61-66.

[3] V.M. Malhotra, Making concrete greener with fly ash, Concr. Int. 21 (1999) 61-66.

[4] OECD, Material Resources, Productivity and the Environment, OECD Publishing, Paris, 2015.

[5] D.W. Rosen, A review of synthesis methods for additive manufacturing, Virtual Phys. Prototyp. 11 (2016) 305-317 http://dx.doi.org/10.1080/17452759.2016. 1240208.

[6] S. Ford, Additive manufacturing and sustainability: an exploratory study of the advantages and challenges, J. Clean. Prod. 137 (2016) 1573-1587 http://dx.doi. org/10.1016/j.jclepro.2016.04.150.

[7] N. Labonnote, Additive construction: state-of-the-art, challenges and opportunities, Autom. Constr. 72 (2016) 347-366 http://dx.doi.org/10.1016/j.autcon.2016.08. 026.

[8] N.M. Alves, P.J. Bártolo, Integrated computational tools for virtual and physical automatic construction, Autom. Constr. 15 (2006) 257-271 http://dx.doi.org/10. 1016/j.autcon.2005.05.007.

[9] B. Khoshnevis, D. Hwang, K.T. Yao, Z. Yeh, Mega-scale fabrication by contour crafting, Int. J. Ind. Syst. Eng. 1 (2006) 301-320 http://dx.doi.org/10.1504/IJISE. 2006.009791.

[10] S. Lim, T. Le, J. Webster, R. Buswell, A. Austin, A. Gibb, T. Thorpe, Fabricating Construction Components Using Layered Manufacturing Technology, Proceedings of the Global Innovation in Construction Conference, Loughborough University, Leicestershire, UK, 2009.

[11] C. Gosselin, R. Duballet, P. Roux, N. Gaudillière, J. Dirrenberger, P. Morel, Largescale 3D printing of ultra-high performance concrete - a new processing route for architects and builders, Mater. Des. 100 (2016) 102-109 http://dx.doi.org/10. 1016/j.matdes. 2016.03.097. 0264-1275.

[12] E. Dini, D-Shape. http://d-shape.com, (2007).

[13] DUS Architects, 3D Print Canal House. http://3dprintcanalhouse.com, (2014).

[14] Winsun, 3D Printing Construction. http://www.yhbm.com, (2014).

[15] WASP, Big Delta. http://www.wasproject.it, (2015).

[16] N. Oxman, Variable property rapid prototyping, Virtual Phys. Prototyp. 6 (2011)
3-31 http://dx.doi.org/10.1080/17452759.2011.558588.

[17] S. Sing, S. Ramakrishna, R. Singh, Material issues in additive manufacturing: a review, J. Manuf. Process. 25 (2017) 185-200 http://dx.doi.org/10.1016/j.jmapro. 2016.11.006.

[18] Y. Miyamoto, W.A. Kaysser, B.H. Rabin, A. Kawasaki, R.G. Ford, Functionally Graded Materials: Design, Processing and Applications, Springer, 1999.

[19] F. Craveiro, J.P. Matos, H. Bártolo, P.J. Bártolo, Automatisation de la construction de bâtiments, in: European Forum on Rapid Prototyping, (2011) Paris, France.

[20] F. Craveiro, J.P. Matos, H. Bártolo, P.J. Bártolo, Automation for building manufacturing, in: P.J. Bártolo, et al. (Ed.), Innov. Dev. Virtual Phys. Prototyp, CRC Press, 2011.

[21] F. Craveiro, J.P. Matos, H. Bártolo, P.J. Bártolo, Advanced Innovation in Building Manufacturing, Fraunhofer Direct Digit. Manuf. Conf. 2012 Berlin, Germany.

[22] F. Craveiro, J.P. Matos, H. Bártolo, P.J. Bártolo, An innovation system for building manufacturing, 11th ASME Conf. Eng. Syst. Des. Anal. 2012 Nantes, France, http:// dx.doi.org/10.1115/ESDA2012-82772.

[23] F. Craveiro, H. Bártolo, P.J. Bártolo, Functionally graded structures through building manufacturing, Adv. Mater. Res. (2013) 775-778 http://dx.doi.org/10. 4028/www.scientific.net/AMR.683.775.

[24] F. Craveiro, H. Almeida, L. Durão, H. Bártolo, P.J. Bártolo, Rapid construction with functionally graded designs, in: H. Bártolo, et al. (Ed.), Green Des. Mater. Manuf. Process, Taylor \& Francis, 2013.

[25] K.L. Scrivener, R.J. Kirkpatrick, Innovation in use and research on cementitious material, Cem. Concr. Res. 38 (2008) 128-136 http://dx.doi.org/10.1016/j. cemconres.2007.09.025.

[26] A.M. Neville, Properties of Concrete, Pitman Publishing Limited, London, 1981.

[27] F. Craveiro, H. Bártolo, J.P. Duarte, P.J. Bártolo, A strategy to locally optimize the material composition of am construction elements, Proc. 2nd int. Conf. Prog. Addit. Manuf. Research Publishing Services, Singapore, 2016, pp. 188-193, , http://dx. doi.org/10.3850/2424-8967V02-122.

[28] B.A. Myers, Taxonomies of visual programming and program visualization, J. Vis. Lang. Comput. 1 (1990) 97-123 http://dx.doi.org/10.1016/S1045-926X(05) 80036-9.

[29] M.Y.H. Bangash, Manual of Numerical Methods in Concrete: Modelling and Applications Validated by Experimental and Site-Monitoring Data, Thomas Telford, London, 2001.

[30] A. Costa, E. Júlio, J. Lourenço, A New Mixture Design Method for Structural Lightweight Aggregate Concrete, 8th FIB PhD Symp, Kongens Lyngby, Denmark, 2010.

[31] Weber, Tabela de Dosagens de Betões Estruturais. http://www.weber.com.pt/ uploads/media/Betoes_Estruturais_Leves_Leca_ISEC.pdf, (2016).

[32] L. Gil, Cork powder waste: an overview, Biomass Bioenergy 13 (1997) 59-61 http://dx.doi.org/10.1016/S0961-9534(97)00033-0.

[33] L.J. Gibson, M.F. Ashby, B.A. Harley, Cellular Materials in Nature and Medicine, Cambridge University Press, 2010.

[34] J. Andrade, Cork Characteristics, Personal Communication, Amorim Isolamentos, S.A., 2016.

[35] R.S. Karade, M. Irle, K. Maher, Influence of granule properties and concentration on cork-cement compatibility, Holz Roh Werkst. 64 (2006) 281-286 http://dx.doi.org/ 10.1007/s00107-006-0103-2.

[36] A. Brás, M. Leal, P. Faria, Cement-cork mortars for thermal bridges correction. Comparison with cement-EPS mortars performance, Constr. Build. Mater. 49 (2013) 315-327 http://dx.doi.org/10.1016/j.conbuildmat.2013.08.006.

[37] A. Mladenovic, J.S. Suput, V. Ducman, A.S. Skapin, Alkali-silica reactivity of some frequently used lightweight aggregates, Cem. Concr. Res. 34 (2004) 1809-1816 http://dx.doi.org/10.1016/j.cemconres.2004.01.017.

[38] L. Cavaleri, N. Miraglia, M. Papia, Pumice concrete for structural wall panels, Eng. Struct. 25 (2003) 115-125 http://dx.doi.org/10.1016/j.clay.2004.01.014.

[39] R. de Gennaro, P. Cappelletti, G. Cerri, M. de'Gennaro, M. Dondi, A. Langella, Neapolitan Yellow Tuff as raw material for lightweight aggregates in lightweight structural concrete production, Appl. Clay Sci. 28 (2005) 309-319 http://dx.doi. org/10.1016/j.clay.2004.01.014 